\title{
Comparison of admission rates to a non-traditional Doctor of Pharmacy programme using internet- based multiple-mini interviews versus on-site
}

\author{
Jennifer D Lake ${ }^{1,2,3}$ (D) , Thomas E R Brown ${ }^{1}$, Kathy $\mathrm{Vu}^{1,4}$, Mina Tadrous ${ }^{1,5,6}$ !if \\ ${ }^{1}$ Leslie Dan Faculty of Pharmacy, University of Toronto, Toronto, Ontario, Canada \\ ${ }^{2}$ Faculty of Medicine, University of Toronto, Toronto, Ontario, Canada \\ ${ }^{3}$ Institute of Health Policy Management \& Evaluation, University of Toronto, Toronto, Ontario, Canada \\ ${ }^{4}$ Cancer Care Ontario, Canada, Toronto, Ontario, Canada \\ ${ }^{5}$ Women's College Research Institute, Women's College Hospital, Toronto, Ontario, Canada \\ ${ }^{6}$ Ontario Drug Policy Research Network (ODPRN), St. Michael's Hospital, Toronto, Ontario, Canada
}

\author{
Keywords \\ Admissions \\ Interviews \\ Pharmacy Education \\ Technology \\ Virtual \\ Correspondence \\ Jennifer Lake \\ Leslie Dan Faculty of Pharmacy \\ University of Toronto \\ 144 College Street \\ Toronto \\ ON M5S 3M2 \\ Canada \\ Jennifer.lake@utoronto.ca
}

\begin{abstract}
Objective: To evaluate if applicants selecting internet-based interviews (iMMI) have the same probability for admission as traditional on-site interviews (MMI). Methods: This was a retrospective cohort study of all applicants between 2014 and 2017 using routinely collected data. Logistic regression was used to compare the odds of admission and models were adjusted for potential confounders. Confounders which were significant in the univariate analysis were selected for the multivariate model. Analysis was performed using XLSTAT. Results: There were 238 applicants. Admission rate was not different between iMMI and $\mathrm{MMI}$ applicants. Eight-four percent (84\%) of applicants in iMMI and $80 \%$ in MMI were admitted leading to a crude odds ratio (OR) of 1.4 (95\% $\mathrm{Cl} 0.7$ - 2.7) and an adjusted OR of $1.2(95 \% \mathrm{Cl} 0.5-2.8)$. Conclusions: This study demonstrated similar admission rates suggesting that $\mathrm{iMMI}$ may be a viable option for wider use. This process may improve admission procedures for hard-to-reach applicants in pharmacy programmes.
\end{abstract}

\section{Introduction}

Admission procedures should be designed to enable selection of students who are most likely to be successful in a given programme. In pharmacy programmes, several different modalities are used to predict the best applicants for their programme. Common criteria for admissions are: cumulative grade point average (cGPA), previous experience, and performance on interviews (Stolte, Scheer, \& Robinson, 2003; Allen et al., 2016). When new admission procedures are used, it is important for programmes to analyse and evaluate them.

By 2020, all Canadian universities must offer the Doctor of Pharmacy (Pharm.D.) as their entry-to-practice professional pharmacy degree (Association of Faculties of Pharmacy of Canada [AFPC], 2010). This followed a similar pattern of change as the American system almost 20 years ago. At University of Toronto, an accessible part-time degree option for pharmacists to achieve their Pharm.D. commenced in 2015. This programme offers twice-yearly admission intakes and is delivered using a combination of didactic and experiential learning. The programme has been designed for working pharmacists by delivering the majority of didactic work online except for one week in the first semester and one weekend in an autumn semester, allowing students to choose their preferred workload each term, and having a four-year timeframe for completion (University of Toronto, 2018). 
MMls are commonly used in medical (Eva et al., 2004; Eva et al., 2012) and pharmacy (Cameron \& Mackeigan, 2012; Cameron et al., 2017) schools for selection of appropriate applicants. Commonly cited limitations of MMls are the heavy demand it places on resources for the faculty and the travel requirement for applicants to participate. As such, interviews are offered on limited days that are convenient for the faculty, thereby requiring the potential applicant pool of working pharmacists to arrange travel and time off around dates that are not necessarily convenient or economical. Internet-based interviewing via Skype (iMMI) was offered to improve the admission process for potential applicants, align with the programme's mandate to provide accessible education where the student is, to encourage applicants from international markets, and to decrease applicants' costs. Previous studies for medical school applicants (Tiller et al., 2013) and selections to medical residency programmes (Shah et al., 2012; Vadi et al., 2016) have shown that internetbased interviews provide similar results to on-site interviews and are feasible for these programmes. No similar information was found for any pharmacy programmes. This study evaluates iMMI as a suitable alternative to $\mathrm{MMI}$ in a non-traditional Pharm.D. programme. The objective of this study was to evaluate if applicants selecting iMMI have the same probability for admission as traditional MMI.

\section{Methods}

This was a retrospective cohort study of applicants who applied for admission between January 2015 and 2018. For applicants with multiple attempts at admission, only their first attempt was included in the analysis. Data were taken from a routinely collected admissions database that contained information from multiple data sources. These sources included: admission application forms, undergraduate pharmacy transcripts, curriculum vitae, application assessments, interview scores, and admission outcomes. This database was completed for all applicants. The admission procedures had two-phases including documentation analysis (Phase 1) with suitable applicants proceeding to a MMI. Internet-based interviewing via Skype (iMMI) was offered in 2014 and potential applicants chose their preferred interview delivery (e.g. on-site (MMI) or internet-based (iMMI)) and their preferred date. At the beginning of the circuit, all iMMI applicants had a Skype session initiated by administrative staff. This Skype session lasted for the entire duration of the circuit. In the $\mathrm{MMI} / \mathrm{iMMI}$ circuit, the interviewers change rooms allowing for a circuit to have both on-site and virtual applicants simultaneously.
In the primary analysis, individuals were identified who completed an interview for admission between January 2015 and January 2018. Demographics were described such as location of undergraduate pharmacy, years since graduation, GPA for undergraduate pharmacy, and current practice setting. Applicants who chose an iMMI or MMI were compared using Chi-square, Student $t$-test, and Mann-Whitney $U$ test as appropriate based on variable type. The primary outcome was the proportion of students admitted to the programme since this is the goal of both the programme and the applicant. Admission was defined as applicants who were offered admission regardless of if they subsequently accepted the programme offer.

Logistic regression was used to compare the odds of admission between interview mediums. Models were adjusted for potential confounders that were not balanced between groups. Potential confounders included factors known to impact admission into pharmacy programmes, or predictors of success and failure in pharmacy programmes or pharmacy practice. The following confounders were analysed for potential inclusion: distance from University of Toronto, cGPA for their undergraduate pharmacy degree, years since graduation, international pharmacy graduate (IPG), and postgraduate training. Postgraduate training included either a previous graduate degree (e.g. M.Sc. or Ph.D.) or previous pharmacy residency training, and pre-interview score (Stolte et al., 2003; Allen et al., 2016). The pre-interview score was a composite assessment of document analysis for each candidate and includes previous academic history, previous pharmacy experience, advocacy, and reference assessment scored as a numerical value ranging from 0 - 8 . Years since graduation from undergraduate pharmacy degree and distance from campus were reported as categorical variables determined by practical estimates and verified in initial analysis. Missing data related to cGPA were input using an average of all GPAs. Confounders with a significant correlation in a univariate analysis were selected for inclusion in the primary multivariable model. Analysis was performed by using XLSTAT (XLSTAT, 2017). $P$-values less than 0.05 were considered as statistically significant. This study was approved by University of Toronto Research and Ethics Board.

\section{Results}

There were 238 applicants from seven admission cycles ranging from $24-51$ interviews per cycle. The group had significant differences in residences' distance from 
university $(p<0.001)$ with more students within $200 \mathrm{~km}$ of the campus in the $\mathrm{MMI}$ and more students $500 \mathrm{~km}$ away or more in the iMMI (Table I). In addition, the mean pre-admission score on document analysis was statistically different ( $\mathrm{MMl}=5$ versus $\mathrm{iMMl}=5.3, p=0.03$ ) but it was not considered to be a meaningful difference. No other differences were statistically significant. Nine applicants in each group were missing GPAs. The various components of the univariate analysis (Table II) are reported with their estimates and confidence intervals for increased likelihood of admission in univariate analysis. The factors which demonstrated significant differences were used in regression analysis. The variable with the largest impact on admission was graduating from a Canadian/American university for bachelor's degree, which univariate analysis showed $8.5(3.9-17)$ increase of admission compared to international pharmacy graduates (IPG).

\section{Table I: Baseline characteristics}

\begin{tabular}{|c|c|c|}
\hline & $\begin{array}{c}\text { MMI (n=122) } \\
n \%\end{array}$ & $\begin{array}{c}\text { iMMI } \\
(n=122) n \%\end{array}$ \\
\hline \multicolumn{3}{|c|}{ Distance of residence from University of Toronto } \\
\hline 0-199 km (reference) & $92(75)$ & $17(15)$ \\
\hline $200-499 \mathrm{~km}$ & $10(8)$ & $11(9)$ \\
\hline $500 \mathrm{~km}$ or more & $20(17)$ & $89(76)$ \\
\hline \multicolumn{3}{|l|}{ Undergraduate University } \\
\hline Canadian/American (reference) & $88(72)$ & $80(69)$ \\
\hline International pharmacy graduates & $34(28)$ & $36(31)$ \\
\hline \multicolumn{3}{|l|}{ Years since graduation } \\
\hline 5 years or less (reference) & $54(44)$ & $56(48)$ \\
\hline $6-10$ years & $37(30)$ & $27(23)$ \\
\hline $11-15$ years & $11(9)$ & $22(19)$ \\
\hline More than 15 years & $22(17)$ & $12(10)$ \\
\hline \multicolumn{3}{|l|}{ Current setting } \\
\hline Community & $59(48)$ & $43(37)$ \\
\hline Hospital (reference) & $48(39)$ & $49(42)$ \\
\hline Other & $16(13)$ & $24(21)$ \\
\hline \multicolumn{3}{|l|}{ Other characteristics } \\
\hline Mean cGPA (Range) & $3.27(1.9-4)$ & $3.33(1-4)$ \\
\hline Postgraduate training & $35(29)$ & $33(28)$ \\
\hline Mean Pre-Interview Score (Range) & $5.0(3-8)$ & $5.3(2-8)$ \\
\hline
\end{tabular}

Overall, the admission rate was not different between two groups with $84 \%$ of applicants being admitted for iMMI and $80 \%$ for $\mathrm{MMI}$, leading to a crude odds ratio (OR) of 1.4 (95\% $\mathrm{Cl} 0.7-2.7)$ and an adjusted OR of 1.2 (95\% Cl 0.5 2.8).
Table II: Univariate analysis of factors affecting admission

\begin{tabular}{|c|c|c|}
\hline \multirow{2}{*}{$\begin{array}{l}\text { Variable } \\
\text { Univariate Analysis } \\
\end{array}$} & & \\
\hline & \multicolumn{2}{|c|}{ Odds Ratio (95\% Cl) } \\
\hline Distance from university & \multicolumn{2}{|c|}{$1(0.86-1.1)$} \\
\hline Postgraduate training & \multicolumn{2}{|c|}{$2.3(0.9-5.6)$} \\
\hline Canadian/American graduate & \multicolumn{2}{|c|}{$8.5(3.9-17)$} \\
\hline Years since graduation & \multicolumn{2}{|c|}{$1.6(1.2-2.2)$} \\
\hline Undergraduate cGPA & \multicolumn{2}{|c|}{$0.5(0.3-0.8)$} \\
\hline Community setting & \multicolumn{2}{|c|}{$0.5(0.3-0.8)$} \\
\hline \multirow[t]{2}{*}{ Pre-interview score } & \multicolumn{2}{|c|}{$0.3(0.2-0.5)$} \\
\hline & $\begin{array}{l}\text { Odds Ratio } \\
(95 \% \mathrm{Cl})- \\
\text { Unadjusted }\end{array}$ & $\begin{array}{l}\text { Odds Ratio } \\
(95 \% \mathrm{Cl})- \\
\text { Adjusted }\end{array}$ \\
\hline Full Multivariable Model & $1.4(0.7-2.7)$ & $1.2(0.5-2.8)$ \\
\hline
\end{tabular}

\section{Discussion}

Delivering iMMI for admission to the non-traditional Pharm.D. programme yielded a similar admission rate as on-site version. As the results showed no difference in the odds of acceptance based on method of interview, applicants selecting the iMMI were not disadvantaged. Applicants residing within $200 \mathrm{~km}$ of University of Toronto chose $\mathrm{MMI}$ and those living outside this area opted for iMMI, this is likely due to costs and convenience as has been found in previous studies (Vadi et al., 2016). This study is consistent with findings in medical education that showed similar admission rates (Vadi et al., 2016) and similar scores between applicants using different interview delivery methods (Shah et al., 2012; Tiller et al., 2013).

The other factors reviewed and used for adjusting the final model were taken from the literature. Being a Canadian/ American graduate was the one factor that most likely predicted admission. Conversely, it is important to consider why IPGs may not have been admitted. It has been documented that IPGs have struggled with academic content, licensing exams, and with practice in Canadian settings (Austin, 2003; Austin \& Galli, 2003; Austin \& Rocchi, 2004; Austin \& Rocchi, 2006). In Austin and colleagues (2003), students' successful completion of the Pharmacy Examining Board of Canada (PEBC) was $90 \%+$ for Canadian trained graduates on first attempt versus less than 40\% for IPG (Austin \& Galli, 2003). Interviews, such as admission to an academic programme, and the Qualifying Exam of PEBC are both high stakes situations which require applicants to access soft skills quickly which may partially explain the differences. Importantly, IPGs were admitted similarly whether they chose iMMI or $\mathrm{MMI}$, so 
the delivery method was not a disadvantage. In data (not shown), more than 67\% IPGs were admitted on subsequent admission cycles.

Another factor which impacted admission was that applicants who practiced in community settings were less likely to be admitted than those in other settings. It was postulated this may be due to correlation with other factors (i.e. IPGs or CGPA). There was no supporting evidence in the literature regarding place of setting as a factor for success in admission procedures. Engaging both IPGs who make up $45 \%$ of Ontario and $30 \%$ of Canadian pharmacist workforce, and the $\sim 70 \%$ of all pharmacists who practice in community will be an important aspect of the ongoing recruitment efforts (Canadian Institute for Health Information [CIHI], 2017). As these were early results of the admission process, these factors will be reviewed in further detail to ensure that the programme supports as many practicing pharmacists who want to increase their clinical skills and knowledge to provide front line patient care services in their communities.

This study has limitations; it was small ( 240 participants) and completed using a pragmatic design with analytics to adjust for baseline differences that may explain different probability of admission. Factors were selected from the literature and not specific to the programme, so an important factor could have been overlooked which impacts admission. However, the analysis did adjust for four significant factors and a line of best fit was completed. To test the robustness of the data, when other models were fit to the data, there were only nonsignificant changes and the point estimate did not change at all with any models. This was early data for the programme's admission and there were slight variations to the admission process. However this was not expected to impact the applicants' likelihood of acceptance and the only outcome available was admission as only a small number of students had completed the programme or left without graduating.

Future study will evaluate the applicant and interviewer experience, predictive modelling of admission factors and success in the programme, and an evaluation of equity throughout the admission process to follow-up new findings which have been generated by this study.

\section{Conclusion}

This study demonstrates admission rates and probability for admission that are similar for both delivery methods of MMI. This provides evidence that iMMI is a suitable process and offers a viable option for schools and colleges of pharmacy. Using iMMI may support improved admission procedures including increasing applicant pool and accessing hard-to-reach applicants.

\section{References}

Allen, R.E., Diaz, C., Gant, K., Taylor, A., \& Onor, I. (2016). Preadmission predictors of on-time graduation in a doctor of pharmacy program. American Journal of Pharmaceutical Education, 80(3), 43. https://doi.org/10.5688/ajpe80343

Association of Faculties of Pharmacy of Canada [AFPC]. (2010). Educational outcomes for first professional degree programs in Canada (entry to practice programs). (Final Summary No. N/A). Vancouver, B.C.: Associations of Faculties of Pharmacy of Canada. Available at: https://www.afpc.info/sites/default/files/AFPC\%20 Educational\%200utcomes.pdf

Austin, Z. (2003). Continuous professional development and foreign-trained health-care professionals. Journal of Social and Administrative Pharmacy, 20(6), 232-241

Austin, Z., \& Rocchi, M. (2004). Bridging education in pharmacy: The international pharmacy graduate program in Ontario, Canada. American Journal of Pharmaceutical Education, 68(5), 108. https://doi.org/10.5688/aj6805108

Austin, Z., \& Galli, M. (2003). Assessing communicative competency of international pharmacy graduates in Ontario, Canada. Journal of Social and Administrative Pharmacy, 20(6), 225-231

Austin, Z., \& Rocchi, M. (2006). Bridging education for foreign-trained professionals: The international pharmacy graduate (IPG) program in Canada. Teaching in Higher Education, 11(1), 19-32. https://doi.org/10.1080/13562510500400081

Cameron, A.J., \& Mackeigan, L.D. (2012). Development and pilot testing of a multiple mini-interview for admission to a pharmacy degree program. American Journal of Pharmaceutical Education, 76(1). https://doi.org/10.5688/ajpe76110

Cameron, A.J., MacKeigan, L.D., Mitsakakis, N., \& Pugsley, J.A. (2017). Multiple mini-interview predictive validity for performance on a pharmacy licensing examination. Medical Education, 51(4), https://doi.org/10.1111/medu.13222

Canadian Institute for Health Information (ClHI). (2017). Pharmacists. Available at: https://www.cihi.ca/en/pharmacists

Eva, K.W., Reiter, H.I., Rosenfeld, J., Trinh, K., Wood, T.J., \& Norman, G.R. (2012). Association between a medical school admission process using the multiple mini-interview and national licensing examination scores. JAMA, 308(21), 2233-2240. https://doi.org/10.1001/jama.2012.36914

Eva, K.W., Rosenfeld, J., Reiter, H.I., \& Norman, G.R. (2004). An admissions OSCE: The multiple mini-interview. Medical Education, 38(3), 314-326. https://doi.org/10.1046/j.1365-2923.2004.01776.x

Shah, S.K., Arora, S., Skipper, B., Kalishman, S., Timm, T.C., \& Smith, A.Y. (2012). Randomized evaluation of a web based interview process for urology resident selection. The Journal of Urology, 187(4), 1380-1384. https://doi.org/10.1016/i.juro. $\underline{2011.11 .108}$ 
Stolte, S.K., Scheer, S.B., \& Robinson, E.T. (2003). The reliability of non-cognitive admissions measures in predicting non-traditional doctor of pharmacy student performance outcomes. American Journal of Pharmaceutical Education, 67(1), 18. https://doi.org/ $\underline{10.5688 / a j 670118}$

Tiller, D., O'Mara, D., Rothnie, I., Dunn, S., Lee, L., \& Roberts, C. (2013). Internet-based multiple mini-interviews for candidate selection for graduate entry programmes. Medical Education, 47(8), 801-810. https://doi.org/10.1111/medu.12224

University of Toronto. (2018). Pharm.D. for Pharmacists Program Requirements. Available at: https://pharmacy.utoronto.ca/ programs/pharmd-pharmacists/pharmd-pharmacists-program-re quirements

Vadi, M.G., Malkin, M.R., Lenart, J., Stier, G.R., Gatling, J.W., \& Applegate, R.L. 2nd. (2016). Comparison of web-based and face-to-face interviews for application to an anesthesiology training program: A pilot study. International Journal of Medical Education, 7, 102-108. https://doi.org/10.5116/ijme.56e5.491a

XLSTAT. (2017). Data analysis and statistical solutions for Microsoft Excel [computer software]. Paris, France: Addinsoft 